\title{
A RESEARCH PROPOSAL FOR THE PROJECT OF IMPLEMENTING ECG TRACKING SENSOR ALARMS IN STREET LIGHT USING SUSTAINABLY PRODUCED ELECTRICITY
}

\author{
Anshika Rana \\ High school graduate, Viveka Foundations School \\ Himachal Pradesh, India
}

\begin{abstract}
The main focus of implementing ECG tracking sensor alarms in street lights using sustainably produced light is to mainframe the idea of using ecofriendly ways to produce electricity as well as enhancing the road security. The idea is to motivate people to enhance physical activities of all ages and using their work force to produce electric power which eventually will contribute to better AI-assisted pedestrian safety system.
\end{abstract}

Keywords - ECG Tracking, Dynamos, Power Generation, Atrial Fibrillation, Sensor Alarms

\section{INTRODUCTION}

Outdoor lighting can enhance function, safety and in some settings, if properly designed for the purpose, it can enhance security. However, street lighting, by its very nature, is focused on vehicular and pedestrian travel safety. Nonetheless, much of the public assumes that street lighting can deter crime despite the fact that there is no reliable objective evidence to support that conclusion. To avoid mis happenings on streets, implementation of sensor alarms in street lights backed by electricity produced by dynamos can be a very product idea in terms of increasing demand of street security. This proposal includes my methods for gathering information, a schedule for completing the review, and my qualifications.

The rest of the paper is organized as follows. Statement of purpose for the research is explained in section II. Objectives are presented in section III. Plan of action for implementation is given in section IV. The conclusion of research is stated in section $\mathrm{V}$ and last section VI is for references.

\section{STATEMENT OF PURPOSE}

Of the total reported rape cases in India, four out of five rape victims are from major 10 states - Rajasthan, Uttar Pradesh, Madhya Pradesh, Maharashtra, Kerala, Assam, Haryana, Jharkhand, Odisha and Delhi. The number of total reported rape cases in these 10 states has almost doubled in the last 10 years - from 12,772 in 2009 to 23,173 in 2019. The rest 26 states have reported almost the same numbers as they did in 2009.

On average, the rape vulnerability of women in India has increased almost four folds over the last 10 years. In 2009, while nearly three women were raped every day in these states, this number went up to 11 for these 10 states in 2019.The most common highlight in these cases is that, $47.32 \%$ of these cases are results of improper safety measures on streets.

The negligence of government to not provide better and secure environment to women folk has led to decline in sex ratio of women in the past decade. This is major issue which require deep concerns for protection of women. Secondly, although electricity is a clean and relatively safe form of energy when it is used, the generation and transmission of electricity affects the environment. In the United States, about $65 \%$ of total electricity generation in 2018 was produced from fossil fuels (coal, natural gas, and petroleum), materials that come from plants (biomass), and municipal and industrial wastes. Nearly all combustion byproducts had negative effects on the environment and human health:

- $\mathrm{CO} 2$ is a greenhouse gas, which contributes to the greenhouse effect.

- $\mathrm{SO} 2$ causes acid rain, which is harmful to plants and to animals that live in water. $\mathrm{SO} 2$ also worsens respiratory illnesses and heart diseases, particularly in children and the elderly.

- NOx contributes to ground-level ozone, which irritates and damages the lungs. 


\section{International Journal of Engineering Applied Sciences and Technology, 2021 \\ Vol. 6, Issue 5, ISSN No. 2455-2143, Pages 293-296 \\ Published Online September 2021 in IJEAST (http://www.ijeast.com)}

- PM results in hazy conditions in cites and scenic areas and coupled with ozone, contributes to asthma and chronic bronchitis, especially in children and the elderly. Very small, or fine PM, is also believed to cause emphysema and lung cancer. - Heavy metals such as mercury are hazardous to human and animal health.

\section{OBJECTIVES}

I propose to review the available street security and developing its features using modern technology. In this review I will achieve the following two goals:

1. Propose a better suitable alternative as a power source to conserve environment and electricity.

2. Enhance the characters of present road security.

Resources that are available to us today should be used economically to conserve them for future use since they are limited and will expire one day. All power generation systems have an environmental impact that must be considered before an investment decision. This is evident when dealing with fossil fuels, since their combustion releases a constant stream of greenhouse gases into the atmosphere. These resources such as coal, oil and gas are not sustainable.

So, rather than exploiting these non-sustainable resources my project proposal, bring forward much fuel-efficient method to control the usage of electricity on a large scale. The key principle of my project is usage of Merry-go-round staples in parks.

According to the Office for National Statistics and Ordnance Survey, England, around 25.4 million people ( 87\%) can access public parks or gardens within a ten-minute walk, while 3.8 million residents $(\sim 13 \%)$ live farther away; of these $21 \%$ are children and $13 \%$ are elderly. Areas with a higher share of flats on average are closer to a park but people living in these areas visit parks that are potentially overcrowded during periods of high use. Urban residents in England and Wales, on average, live 557 meters away from their closest park or garden. Ten percent of the population ( 2.8 million) has at least one park in the immediate vicinity of their residence ( $<100$ meters), $59 \%$ (14.4 million) within 500 meters, $28 \%$ (8.3 million) between 500 to 1,000 meters, and $13 \%$ (3.8 million) live more than 1,000 meters from a public park or garden.

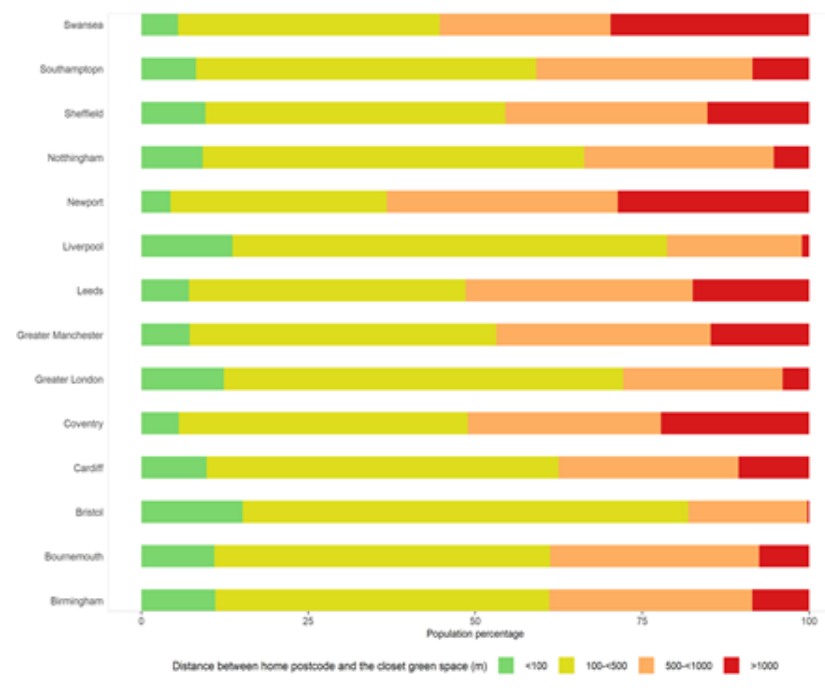

Percent of population in categories of distance to the nearest park or garden for 14 cities in England and Wales.

https://doi.org/10.1371/journal.pone.0241102.g002

Similarly, from the stated facts from Seoul Parks Data \& Annual Statistics (1945- 2014), there are nearly 13,692 local and facility parks alone in Seoul at present, approximately covering a land of $3,546,130 \mathrm{~m}$.sq. These huge number of parks can be utilized to generate power along with practicing performing activities. An average of 2 Merry-go-round staples at every park can generate sufficient rotations to produce enough electricity to light the streets at night without harming nature. In England, ten percent of the population (2.8 million) has at least one park in the immediate vicinity of their residence (< 100 meters), 59\% (14.4 million) within 500 meters, which alone can produce a huge amount of electricity to glow up the whole city, even with the minimum play time of 5 minutes per person.

\section{PLAN OF ACTION}

The major theme of my proposal is production of electricity through ecofriendly means. Through the data used in my project, my research aims to accomplish the objective. The basic idea of my project is to use Merry-go-round slides to produce electricity. The foremost principle of this staple is to rotate. Every single rotation of merry-go-round can be utilized to generate power supply through the medium of electric dynamo. This rotation motion works as a turbine providing the mechanical power source. A shaft from one of these turbines is connected to a generator to make power. 

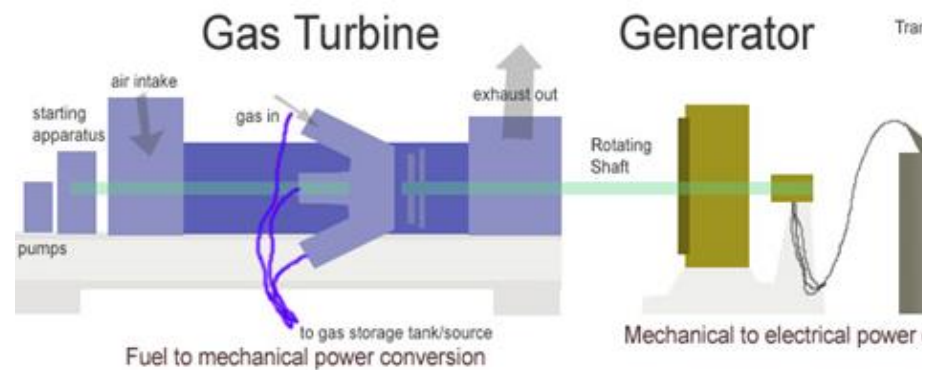

Dynamo's work using the wild complex phenomena of electromagnetism. In the most basic sense, a dynamo as a magnet will rotate while inside the influence of another magnet's magnetic field. We cannot see this magnetic field, but will illustrate it using lines of flux.

The dynamo is made up of stationary magnets (stator) which will create a powerful magnetic field, and a rotating magnet (rotor) which will distort and cut through the magnetic lines of flux of the stator. When the rotor will cut through lines of magnetic flux it makes electricity. The electric dynamo uses rotating coils of wire and magnetic fields, to convert mechanical rotation into pulsing a direct electric current through Faraday's law of induction.

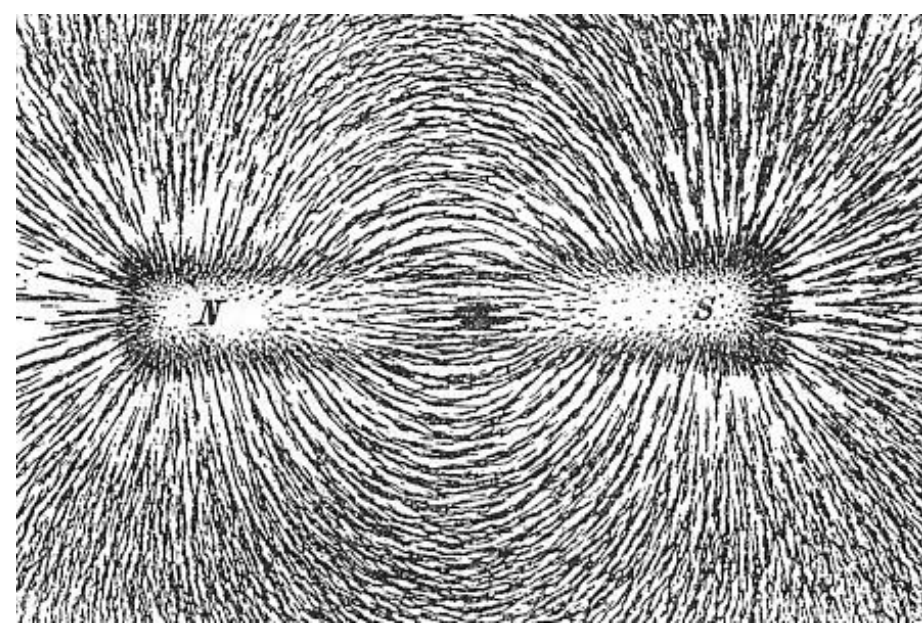

Due to Faraday's Law of Induction, when wire will be moved back and forth in a magnetic field, the field pushes on electrons in the metal. The magnets are usually not made of natural magnetite or a permanent magnet, but they are copper or aluminum wire coiled around an iron core. Each coil will be energized with some power to make it into a magnet. Coil around iron is called a solenoid. Solenoids are used instead of natural magnetite because the solenoid is much more powerful. A small solenoid can create a very strong magnetic field.
The stator will make the magnetic field. Large dynamos require an electromagnet. The armature is made of coiled copper windings, which rotate inside the magnetic field made by the stator. When the windings move, they cut through the lines of magnetic field. This creates pulses of electric power. The commutator will produce direct current. In direct current power flows in only one direction through a wire, the problem is that the rotating armature in dynamo reverses current each half turn, so the commutator is a rotary switch that disconnects the power during the reversed current part of the cycle. Brushes are part of the commutator; the brushes must conduct electricity as the keep contact with the rotating armature.

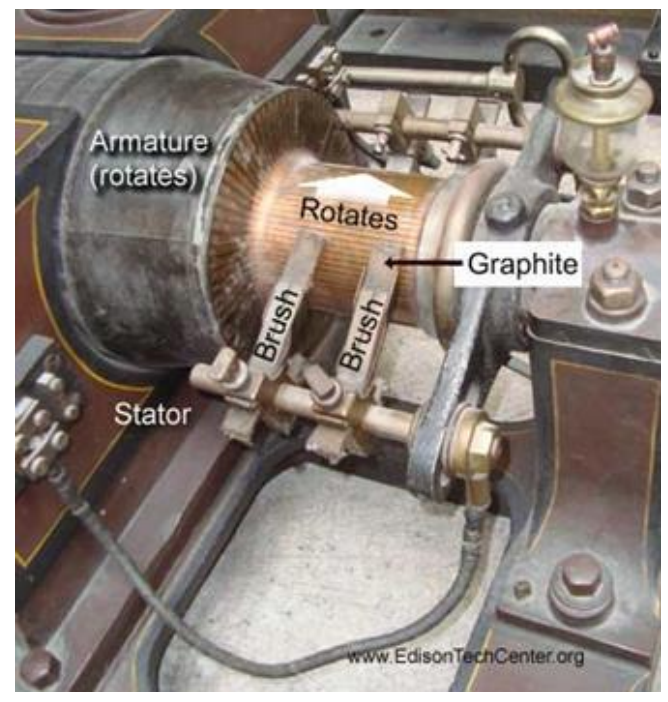

The core idea of my project in simple. The amount of current produced through these slides can provide sufficient electricity to the street light on every day bias. The production is economically beneficial and environmentally friendly.

The second main objective of my projects is execution of ECG tracking sensor alarms in streets lamps. As safety is the first priority, implementation of these alarms will help to reduce crime cases. Ambulatory electrocardiogram (AECG) monitoring allows the noninvasive evaluation of a suspected arrhythmia during normal daily activities. It aids in the diagnosis, documentation of frequency, severity, and correlation of an arrhythmia with symptoms such as palpitations, lightheadedness, excitement, fear or overt syncope.

Using light beams and light sensitive sensor alarms, changes in the blood volume passing through the wrist caused by the peripheral pulse will be measured to generate a PPG, which will then use to estimate the heart rate.[1] The "peak" to "peak interval between pulsations can be interpreted as the cardiac $\mathrm{R}$ $\mathrm{R}$ interval [2], and can be incorporated into an algorithm to detect atrial fibrillation (AF). Different groups have created AF 


\section{International Journal of Engineering Applied Sciences and Technology, 2021 \\ Vol. 6, Issue 5, ISSN No. 2455-2143, Pages 293-296 \\ Published Online September 2021 in IJEAST (http://www.ijeast.com)}

detection algorithms [3], [4] and accuracy of such algorithms can be affected by ectopic beats, motion, environmental conditions, as well as adequate blood flow, among other factors. [5]

Using PPG technology, the alarm will record a tachogram which is a plot of the time between heartbeats and then applies its proprietary algorithm to determine pulse irregularity and thus AF.

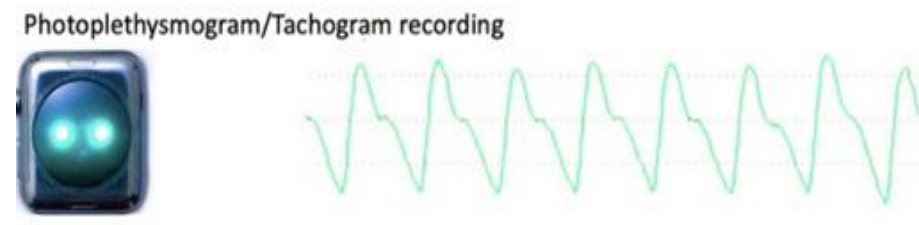

Demonstration of the photo Tachogram recording using alarm using light beams to record changes in the blood volume passing through the hand.

A single lead electrocardiogram (ECG) can be recorded through a circuit between the detector on the button of alarm and the digital crown. Rhythm analysis will be reported after $30 \mathrm{~s}$ of recording. The signal classifies an ECG as sinus rhythm (SR), AF or inconclusive. Recordings from the alarm will recorded and through the detection of ECG and atrial fibrillation (AFIB) of the person pressing the alarm, a direct emergency signal will be sent to the nearest police station and a siren will automatically come into action if the person is I danger. The alarm will only respond if individual is actually unsafe, depending upon the heart rate of the person or else not.

Most of these technologies are available in market through watches, wrist bands etc. But affording these devices is not possible to everyone. My proposal will help towards the better security measures for government as well as safety of mainly women in so many countries.

\section{CONCLUSION}

This document has proposed research project to evaluate the possibility of using dynamos for ecofriendly production of electricity. The project will include a formal presentation of the idea of electricity generation and implementation of ECG tracking sensor alarms in street lamps. The proposed project will achieve the following goals:

(1) Propose a better suitable alternative as a power source to conserve environment and electricity.

(2) Enhance the characters of present road security. For further information about my qualifications, see the attached resume.

\section{REFERENCES}

1. Natural England. Monitor of Engagement with the Natural Environment-The national survey on people and the natural environment.

2. Mayor of London. London Parks and Green SpacesCOVID-19 Guidance 2020. https://www.london.gov.uk/coronavirus/socialdistancing-guidance/london-parks-and-green-spacescovid-19-guidance.

3. Zhang $\mathrm{X}, \mathrm{Lu} \mathrm{H}$, Holt JB. Modeling spatial accessibility to parks: a national study. Int J Health George. 2011;10(1):31. pmid:21554690

- $\quad$ View Article

- PubMed/NCBI

- Google Scholar

4. S. Nemati, M.M. Ghassemi, V. Ambai, N. Isakadze, O. Levantsevych, A. Shah, et al.

5. Monitoring and detecting atrial fibrillation using wearable technology Proceedings of the conference on IEEE engineering in medicine and biology society, 2016 (2016), pp. 3394-3397

6. Seoul Solution, Green Parking Project as a Service to Citizens.doc "Changes in Park \& Green Space Policies in Seoul"

7. The General Electric Story - by The Hall of History, Schenectady, NY 1989

8. Second Edition Hawkins Electrical Guide, History of AC Power - Edison Tech Center DC Pandey, "Understanding Physics", Mechanics, Vol.2

9. Soumya Joy, "Smartwatches with ECG Tracker to Monitor the Health of Your Heart" (The Times of India, 2021) 